
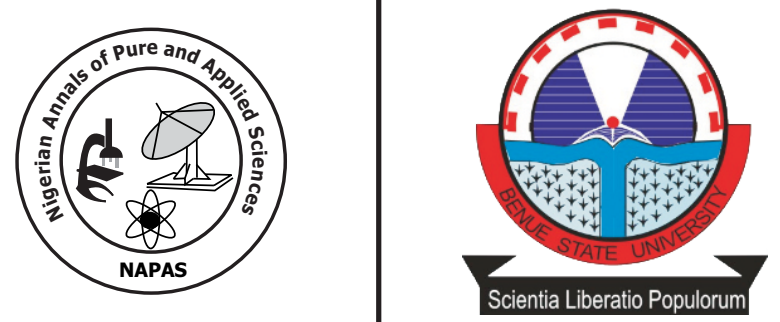

pp 230.239

\title{
Stochastic Modeling of Net Radiation conditioned on Wind Speed
}

\author{
Agada, I.0. ${ }^{1}$, Sombo, T. ${ }^{2}$ and Utah, E.U. ${ }^{3}$ \\ 1,2 Department of Physics, \\ University of Agriculture, Makurdi, \\ Benue State, Nigeria. \\ ${ }^{3}$ Department of Physics, \\ University of Uyo, Akwa Ibom State, Nigeria.
}

\begin{abstract}
This study aims at modeling net radiation conditioned on wind speed in Port Harcourt using the stochastic (Markov chain model) approach. Thirty-four (34) years data (1977-2010) on daily maximum and minimum relative humidity, maximum and minimum air temperature, solar irradiance and wind speed were sourced from the International Institute of Tropical Agriculture (IITA) and used in the analysis. A two - state (surplus net radiation conditioned on high wind speed and surplus net radiation conditioned on low wind speed) Markov Chain model was developed and used in the course of this work. The result revealed that net radiation is surplus all through the year and monthly steady state probabilities (long run dependence) of surplus net radiation conditioned on low wind speed dominate all through the year. Further analysis with the model showed that surplus net radiation conditioned on low wind speed would occur for 2.44 days and surplus net radiation conditioned on high wind speed for 1.69 days on the average, resulting to a hot weather and climate.
\end{abstract}

Key words: Surplus net radiation, Stochastic, Markov Chain, wind speed. 


\section{Introduction}

Meteorologists build models to study the weather and climate because they can't experiment with the weather and climate in the laboratory. The mathematical models (either analytical or numerical) can be divided into two categories, namely stochastic and deterministic models. These models can be used to describe physical reality. A stochastic model predicts a set of possible outcomes in terms of their likelihoods or probabilities, while a deterministic model are usually expressed in terms of differential equations and predict a single outcome from a given set of circumstances. The choice of using a deterministic or a stochastic model depends among other things on the nature of the process to be modeled. A process that is complex, involves many discrete events and has a strong element of random motion, a stochastic model is appealing for such processes (Dechsiri, 2005).

It is difficult to model climatic variables deterministically due to their random (stochastic) behavior and multicollinearity (Nortazi, et al., 2013). Random variables cannot be predicted exactly; it depends on chance events of which probability values can be used to describe the likelihood that these random variables will occur. These random variables are either discrete (such as positive integers) or continuous (take on any values within a specified range of values). A discrete or continuous random variable whose value changes through time according to probabilistic laws is called a stochastic process. One general assumption of a stochastic process is that the process is stationary (the probability distribution of the process is not changing over time). Stochastic processes can be categorized into four groups, namely discrete state in discrete time, discrete state in continuous time, continuous state in discrete time and continuous state in continuous time model used in the development of a random system over the course of time (Dechsiri, 2005). The nature of the physical processes considered in this research, calls for a model with discrete state in discrete time stochastic process (Markov Chain model) in modeling net radiation conditioned on wind speed.

The difference between the incoming solar (shortwave) radiation that reaches the earth's surface and the total terrestrial (longwave) radiation that is being emitted from the earth's surface is termed net radiation (Lincoln et al., 2015). This difference between the incoming solar radiation and the emitted terrestrial radiation creates an adiabatic heat sink (cool down) over the polar-regions and heat source (warm up) over the equatorial latitudes. Excess heat (surplus net radiation) from the equatorial region must be transferred by wind to the polar region (deficit net radiation), in order to balance the heat energy between the two regions. These factors control the nature of climate and lead to very distinctive climates in diverse regions of the world. So many authors have worked solely on either wind speed, the estimation of net radiation, wind speed and solar Irradiance combined using the deterministic approach. However, only few have applied the stochastic approach. Danilton et al. (2018) used two empirical methods (Gauss and Practical) in estimating reference surface net radiation from solar radiation. The result obtained revealed that both estimating methods showed satisfactory results, with relative mean absolute error values lower than 5.8\%. Philip and Hazel (2015) worked on the climatological relationships between wind and solar energy supply in Britain. D'Amico et al. (2012) studied the First and second order semi-Markov chains for wind speed modeling. They noticed that the second order semi-Markov process is more suitable in state and duration and concluded that semiMarkov models should be used when dealing with wind speed data. This work seeks to estimate net radiation using the Penman Monteith (FAO-56) model. Santiago et al. (2002) and Gavilán et al. (2007) recommended the use of Penman Monteith (FAO-56) model in computing net radiation $(R n)$, given that Von Randow and Alvalá (2006) and Galvão and Fisch (2000) encounter difficulties in computing net longwave (terrestrial) radiation using the FAO-24 equation. This study differs from previous works, as they rarely conditioned net radiation on wind speed in Port Harcourt using the Markov Chain modeling approach. According to Crommelin and Khouider (2015), climate predictions and weather forecasts should be expressed in terms of probabilities due to their random (stochastic) behavior.

Port Harcourt is in the south-south of Nigeria, and the capital of Rivers State. It lies within Longitude $7.0498^{\circ} \mathrm{E}$ and latitude 
$4.8156^{\circ} \mathrm{N}$ (Oyewole and Aro, 2018). The rainy season is from February to October and the air stream (South-west trade winds) blows over the area within these months to transport moisture along the coast line. The North-East trade winds is responsible for the dry conditions experienced from November to February (dry season), having passed over the hot dry Sahara desert to reach Port Harcourt from the North (Uko and Tamunobereton-Ari, 2013).

\section{Theoretical Framework}

\section{Penman-Monteith (FAO-56) Model.}

Due to high cost and constant maintenance of recording instruments such as net radiometers, net radiation $\left(R_{n}\right)$ measurements are difficult to collect. The Penman-Monteith (FAO-56) step by step method was used to compute the daily net radiation. This includes:

The inverse relative distance Earth-Sun ( $r \partial$ is given as (Spencer, 1971):

$\partial r=1+0.033 \cos \left[\frac{2 \pi}{365} j\right]$

where $j$ is number of the day in the year between 1 (1 January) and 365 or 366 (31 December).

The solar declination $(\delta)$ can be found from the approximate equation of Cooper (1969),

$\delta=23.45 \sin \left(360 \frac{284+j}{365}\right)$

The sun angle) ( $\omega_{s}$ is given by ( $\mathrm{John}$ and William, 2013):

$\omega_{s}=\arccos [-\tan (\varphi) \tan (\delta)]$

where $\varphi$ is the latitude of a particular location.

The extraterrestrial radiation $(a R$, ) for each day of the year can be estimated using;

$R_{a}=\frac{24 \times 3600}{\pi} G_{s c} \partial r\left(\cos \varphi \cos \delta \sin \omega_{s}+\frac{\pi \omega_{s}}{180} \sin \varphi \sin \delta\right)$

where $G_{s c}$ is solar constant $=1367 \mathrm{w} / \mathrm{m}^{2}$ (lgbal, 1983).

The actual vapor pressure $\left(e_{a}\right)$ can be computed (Lincoln et al., 2015);

$$
\begin{aligned}
& e_{a}=\frac{e_{\left(T_{\min }\right)}\left[\frac{R H_{\max }}{100}\right]+e_{\left(T_{\max }\right)}\left[\frac{R H_{\min }}{100}\right]}{2} . \\
& e_{\left(T_{\max }\right)}=0.6108 \exp \left(\frac{17.27 T_{\max }}{T_{\max }+237.3}\right) \\
& e_{\left(T_{\min }\right)}=0.6108 \exp \left(\frac{17.27 T_{\min }}{T_{\min }+237.3}\right)
\end{aligned}
$$

where $e_{\left(T_{\min }\right)}$ and $e_{\left(T_{\max }\right)}$ are daily saturation vapour pressure at minimum and maximum temperature, and $R H_{\text {max }}, R H_{\text {min }}$ are maximum and minimum relative humidity.

The clear-sky radiation $R_{s o}$ is given by (Lincoln et al., 2015):

$$
R_{s o}=(0.75+2 E 10-5 Z) R_{a}
$$

where $Z$ is the elevation above sea level.

The net terrestrial (long wave) radiation $\left(R_{T}\right)$ is proportional to the absolute temperature of the surface rais ed to the fourth power. This relation is expressed quantitatively by the Stefan-Boltzmann law as given below: $R_{T}=\sigma$ $\left[\frac{\left(T_{\max }+273.16\right)^{4}+\left(T_{\min }+273.16\right)^{4}}{2}\right]\left(0.34-0.14 \sqrt{\left.e_{a}\right)}\left[1.35 \frac{R_{s}}{R_{s 0}}-0.35\right] 7\right.$ where $\sigma$ is Stefan -Boltzmann constant $\left[4.903 \times 10^{-9} \mathrm{MJ} \mathrm{K}^{-4} \mathrm{~m}^{-2}\right.$ day $\left.^{-1}\right]$ and $R_{s}$ is incoming solar radiation, $\mathrm{MJm}^{-2}$ day $^{-1}$. Lastly, the net radiation $\left(R_{n}\right)$ which is the difference between the incoming net shortwave radiation $\left(R_{n s}\right)$ and the outgoing net terrestrial radiation $\left(R_{T}\right)$ is given by;

$R_{n}=R_{n s}-R_{T}$

$R_{n s}=(1-a) R_{s}$

where $a$ is albedo $=0.3$ (John and Willam, 2013).

\section{Markov Chain}

Markov chain is a stochastic process $\left\{X_{n}, n=\right.$ $0,1,2, \ldots \ldots$ that takes on a finite or countable number of possible values and if $X_{n}=i$, then the process is said to be in state $I$ at time $n$. Supposing that the process is in state $i$, there is fixed probability $P_{i j}$ that it will next be in state $j$. That is;

$P\left\{X_{n+1}=j \mid X_{n}=i, X_{n-1}=i_{n-1}, \ldots, X_{1}=i_{1}, X_{0}=i_{0}\right\}$
$=P\left\{X_{n+1}=j \mid X_{n}=i\right\}=P_{i j}$

For all states $i_{0}, i_{1}, \ldots, \quad i, \quad j$ and $n=0$. For a first-order Markov chain, the future state $X_{n+1}$ is independent of the previous states $\left(X_{0}, X_{1}, \ldots \ldots, X_{n-1}\right)$, but depends only on the present state $X_{n}$ (Ross, 2010). 


\section{Transition Probability Matrix}

A Markov chain transition matrix is a square array describing the probabilities of the chain transiting from one state to another. This transition probability $P_{i j}$ is given as (Balzter, 2000):

$P_{i j}=\left(\begin{array}{cccc}p_{11} & p_{12} & \cdots & p_{1 n} \\ p_{21} & p_{22} & \cdots & p_{2 n} \\ \cdots & \cdots & \cdots & \cdots \\ p_{n 1} & p_{n 2} & \cdots & p_{n n}\end{array}\right)$

The elements $P_{i j}$ are also called stationary probabilities. They are defined by:

$P\left(X_{n}=j / X_{n-1}=i\right)=p_{i j}$

Considering the long period of the daily net radiation (34 years) used in this work, the $P_{i j}$ 's are assumed stationary.

\section{N-Step Transition Probability Matrix}

For any value of $n\left(n=2,3 \ldots\right.$, the $n^{\text {th }}$ power of the matrix $P$ specify the probabilities $p_{i j}^{n}$ that the chain will move from state $x_{i}$ to $x_{j}$ is called the n-step probability matrix. This is based on the Chapman Kolmogorov equation, which states as follows;

For any $r \leq n$,
$P_{n}=\left(P_{i j}\right)_{n}=P^{(n)}=\sum_{k=0}^{\infty} P_{i k}^{r} P_{k j}^{n-r}$

where $P_{n}$ denotes the matrix of n-step transition probability (Udom, 2010).

\section{Steady State Probabilities of a Markov Chain}

Consider a Markov chain with Z-states and the row vector

$\pi=\left(\pi_{1} \pi_{2} \ldots \ldots \ldots \ldots \pi_{z}\right)$

such that
(i) $\pi_{i} \geq 0$
(ii) $\sum_{i=1} \pi_{i}=1$
(iii) $\pi_{j}=\lim p_{i j}^{n}$

Where $P\left\{X_{n+1}=j \mid X_{n}=i\right\}=P_{i j}$

$\left(\pi_{1} \pi_{2} \ldots \ldots \ldots \ldots \pi_{z}\right)$ is called the steady state vector of the Markov Chain. $\pi$ can be obtained by solving the relation;

$\pi=\pi P_{i j}$

where $P_{i j}$ are the stationary probabilities.

\section{Methodology}

\section{Source of Data}

The daily maximum and minimum Relative-Humidity, maximum and minimum air temperature, solar radiation and wind speed data were obtained from the International Institute of Tropical Agriculture (IITA) Ibadan, Nigeria for the period of thirty -four (34) years (1977-2010). The daily data $w$ as used in computing the daily Actual vapor pressure ( $e_{a}$ ), and Terrestrial (long wave) radiation $\left(R_{T}\right)$. The daily inverse relative distance Earth -Sun $(\partial r)$, Solar declination $(\delta)$, sun angle $\left(\omega_{s}\right)$, extraterrestrial radiation $\left(R_{a}\right)$,Clear sky solar radiation ( $R_{s o}$ ), and Net radiation ( $R_{n}$ ) were also computed using the step by step Penman Monteith model (equation 1 -9). Lastly, the daily net radiation and wind speed was arranged monthly over the period of the thirty four years (1977 -2010) and the monthly average was computed.

\section{Data transformations employed in the modeling process}

The daily wind speed data and the daily computed net radiation over the period (19772010) was transformed into a sequence of binary events. For any $K^{\text {th }}$ day, a random variable $R_{n k}$ is defined to represent this event with the realization; 0 if the daily net radiation $\left(R_{n}\right)$ is negative (deficit) and with realization ' 1 ' if the daily net radiation $\left(R_{n}\right)$ is positive (surplus). We also define a random variable $W_{k}$ for daily wind speed $(W)$ with realization; 0 if ' $W$ ' is below monthly grand average $(\bar{W})$ and with realization ' 1 ' if the daily wind speed $(W)$ is above monthly grand average $(\bar{W})$. This is termed low and high wind speed respectively. Mathematically we have;

$$
W_{k}=\left\{\begin{array}{l}
\left.0, \text { if } W_{k}<\bar{W} \text { (low wind speed }\right) . \\
\left.1, \text { if } W_{k} \geq \bar{W} \text { (high wind speed }\right) .
\end{array}\right.
$$

$R_{n k}=\left\{\begin{array}{l}0, \text { if } R_{n k}<0 \text { (deficit net radiation). } \\ 1, \text { if } R_{n k}>0 \text { (surplus net radiation). }\end{array}\right.$ 
where $k$ is $1,2, \ldots, n$ (days); $W$ and $\bar{W}$ are daily wind speed and grand monthly average wind speed respectively.

It is observed that net radiation is completely surplus all through the year in Port Harcourt, Nigeria as presented in Figure 1 Therefore, in order to model the relationship between net radiation and wind speed, we define a new transformation as follows. For any $K^{\text {th }} d a y$, we capture a sequence of binary events using a random variable $X_{k}$ with the realizations ' 1 ' if $R_{n k}$ is 1(surplus) and $W_{k}$ is 1 (high) and ' 2 ' if $R_{n k}$ is 1 (surplus) and $W_{k}$ is 0 (low). Conditioning surplus net radiation on high and low wind speed was done daily for each month. Mathematically, we have;

$X_{k}=\left\{\begin{array}{l}1, \text { if net radiation is } 1 \text { and wind speed is } 1(S / H) \\ 2, \text { if net radiation is } 1 \text { and wind speed is } 0(S / L) .\end{array}\right.$

where $\mathrm{S} / \mathrm{H}$ and $\mathrm{S} / \mathrm{L}$ are Surplus net radiation conditioned on high and low wind speed. The Microsoft Excel Package (2007) was used to implement this transformation, for accuracy and computational ease.

In this study, the steady state probabilities for the first order Markov chain model were determined using the computational formula:

$$
\pi_{1}=\frac{p_{01}}{1+p_{01}-p_{11}}
$$

$\pi_{2}=1-\pi_{1}$ and $1=\pi_{1}+\pi_{2}$ where and are steady state probabilities of surplus net radiation conditioned on high wind speed and surplus net radiation conditioned on low wind speed respectively. The mean recurrence time (in days) for each state is modeled as:

$1 / \pi_{1}$ and $1 / \pi_{2}$

Due to the huge amount of data involved in this work, a computer program was written in Pascal programming language version 1.5 for obtaining the transition counts, transition probabilities, $\mathrm{N}$-step transition matrix and steady state probabilities.

\section{Results and Discussion Monthly Net radiation and Wind speed}

Net radiation is surplus in Port Harcourt from January to December as presented in Figure 1. Surplus net radiation tends to increase the air temperature of a place, thus the excess surplus net radiation must be transferred by high wind speed to deficit net radiation region. Once people are exposed to severe heat, they undergo deadly illnesses, such as heat stroke and heat exhaustion. Therefore, the transfer of heat continues until both the warmer and cooler bodies attain the same temperature. Average monthly wind speed in Port Harcourt increases and decreases from January to December as shown in Figure 1 having it highest and lowest values in the months of April and December respectively.

$$
\pi_{1} \quad \pi_{2}
$$

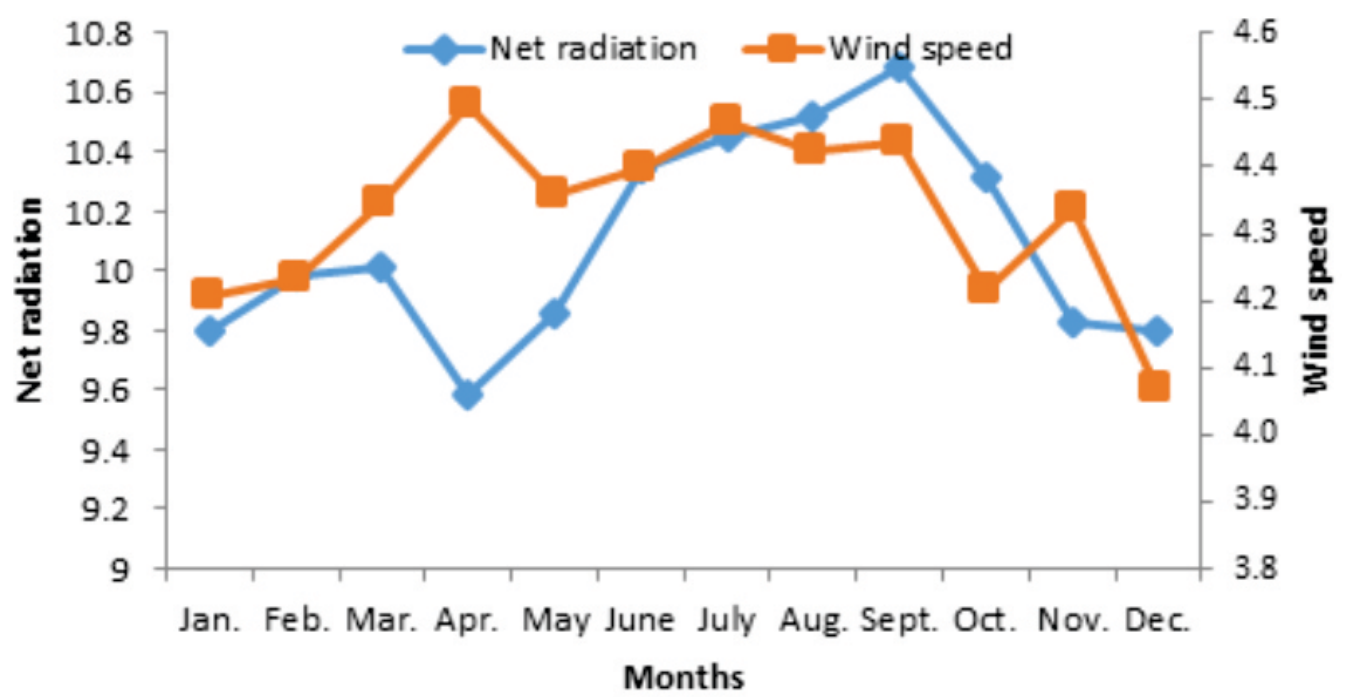

Figure 1: Average monthly net radiation and wind speed. 
Surplus net radiation is maximum in the month of September and minimum in April. This implies that the month of April would be relatively cooler compared to other months because the surplus net radiation is transferred by excess high wind speed to deficit net radiation regions. This result agrees with the work of Uko and Tamunobereton-Ari (2013). They correlated the monthly variation of weather conditions of rainfall, humidity, temperature, solar radiation, and evaporation with each other in order to deduce climatic changes over the ten year period. They observed that the rainy season is from February to October and the air stream (South-west trade winds) blows over the area within these months to transport moisture along the coast line.

\section{First order transition probability matrix}

The first order transition probability matrix is obtained by dividing each transition counts as presented in Table 1 by the total transition row wise in a matrix form.

Table 1: Transition Counts of surplus net radiation conditioned on high or low wind speed.

\begin{tabular}{lcccccccccccc}
\hline SEQ. & JAN. & FEB. & MAR. & APR. & MAY & JUNE & JULY & AUG. & SEPT. & OCT. & NOV. & DEC. \\
\hline S/H-S/H & 163 & 141 & 170 & 197 & 149 & 174 & 194 & 167 & 162 & 144 & 127 & 160 \\
S/H-S/L & 102 & 98 & 96 & 100 & 112 & 95 & 99 & 98 & 85 & 110 & 99 & 124 \\
S/L-S/H & 102 & 97 & 97 & 100 & 113 & 96 & 99 & 97 & 85 & 109 & 99 & 123 \\
S/L-S/L & 203 & 256 & 287 & 232 & 276 & 264 & 256 & 288 & 297 & 287 & 304 & 243 \\
\hline
\end{tabular}

$\mathrm{S} / \mathrm{H}$ is surplus net radiation conditioned on High wind speed; $\mathrm{S} / \mathrm{L}$ is surplus net radiation conditioned on low wind speed; - is transition

The transition probabilities of surplus net radiation conditioned on low wind speed transiting into the same state dominates all through the year, having its highest and lowest peck in the months of

September $(0.78$ or $78 \%)$ and December $(0.66$ or $66 \%)$ as presented in Figure 2.

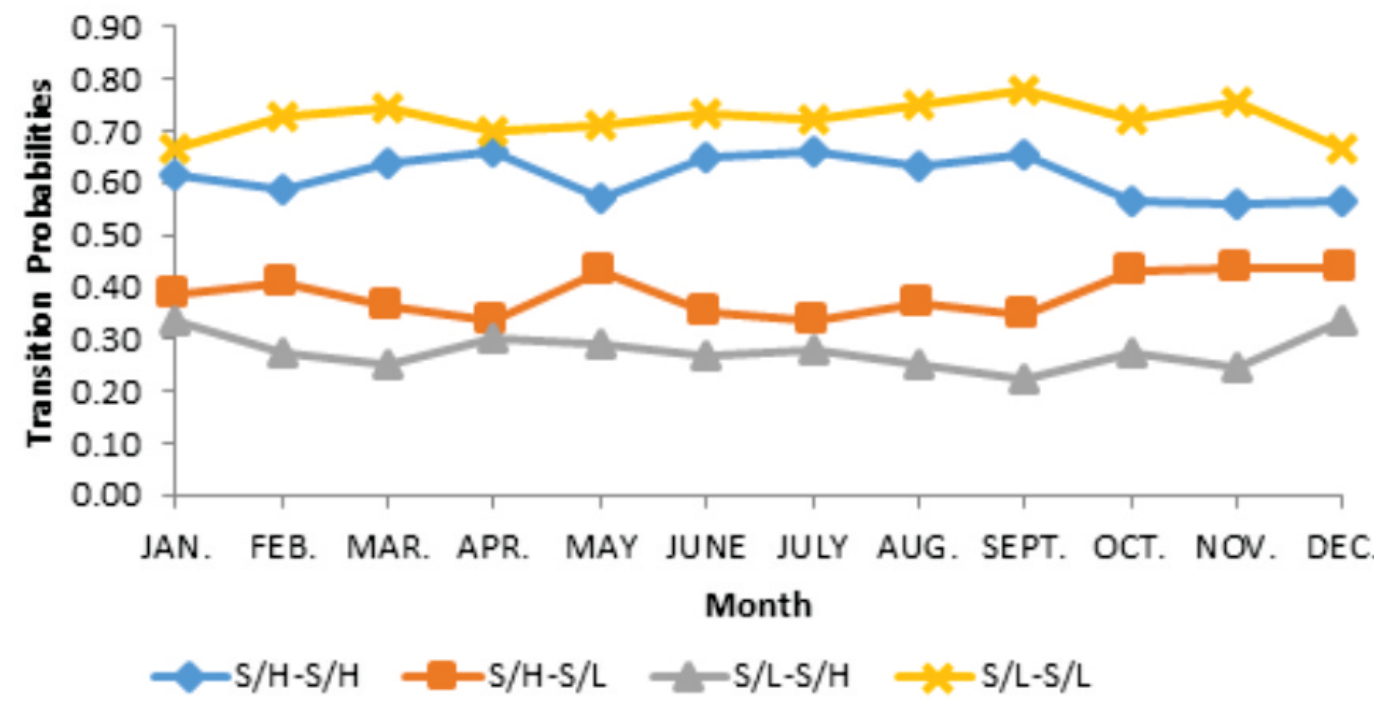

Figure 2: Transitions probabilities of a particular state transiting into another state.

Equal transiting probabilities of surplus net radiation conditioned on low wind speed transiting into the same state is observed in the months of March, August, September and November $(0.75$ or $75 \%)$; also in the months of February and June $(0.73$ or $73 \%)$; lastly, the months of July and October $(0.72$ or $72 \%)$ as shown in Figure 2. This implies that there is a $75 \%$ chance of surplus net radiation conditioned on low wind speed transiting into the same state in the months of March, August, September and November. Similarly, the transition probabilities of surplus net radiation conditioned on high wind speed transiting into 
the same state are the same in the months of April, July and September (0.66 or $66 \%)$; also November and December ( 0.56 or $56 \%$ ); lastly, May and October $(0.57$ or $57 \%)$ as shown in Figure 3. This implies that there is a $57 \%$ chance of surplus net radiation condition on high wind speed transiting into the same state in the months of May and October.

The transition probabilities of surplus net radiation conditioned on high wind speed transiting into a surplus net radiation conditioned on low wind speed and surplus net radiation conditioned on low wind speed transiting into a surplus net radiation conditioned on high wind speed is below 0.45 . This means that, the chance of this transitions occurring is less than $45 \%$ as presented in Figure 2. Surplus net radiation conditioned on low wind speed transiting into the same state has the highest chance of occurring from January to December, resulting to an increase in air temperature in Port Harcourt month in month out.

\section{Steady state probabilities.}

Surplus net radiation conditioned on low wind speed has the highest monthly steady state probabilities (long run dependence) from January to December as shown in Figure 3, having its highest and lowest probabilities in the months of November and April respectively.

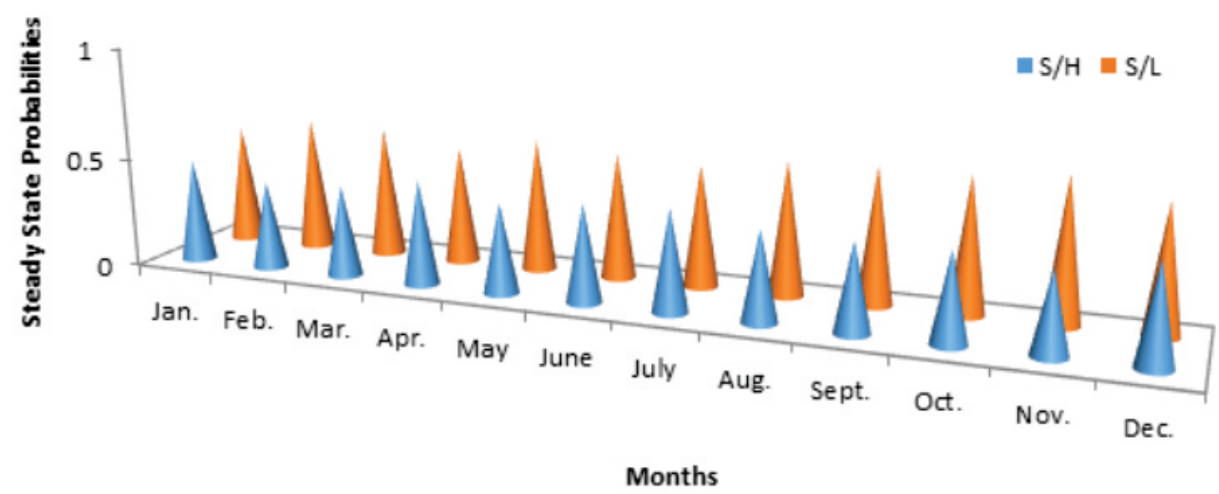

Figure 3: Monthly steady state probabilities of surplus net radiation conditioned on High and Low wind speed $(S / H$ and $S / L)$

The month of November would be warmer compare to the month of April, because more heat is being retained in the month of November. The month of April experiences the highest amount of wind speed as shown in Figure 1. This explains why April has the lowest steady probability when net radiation was conditioned on wind speed. Hence, more of the surplus net radiation will be transferred by this high wind speed in the month of April to deficit net radiation region, thereby decreasing the air temperature.

The steady states probabilities of surplus net radiation conditioned on low wind speed are the same in the months of May and August ( 0.60 or $60 \%$ ). Similarly, it is also observed that equal steady state probabilities of surplus net radiation conditioned on high wind speed occurs in the months of May and August ( 0.40 or $40 \%)$ as presented in Figure 3. This signifies that at the long run, there is a chance of $60 \%$ surplus net radiation conditioned on low wind speed and
$40 \%$ surplus net radiation conditioned on high wind speed occurring in the months of May and August. It is also observed that in Figure 1, surplus net radiation occurs all through the year. Thus, Figure 3 reveals that $47 \%$ and $36 \%$ of surplus net radiation are transferred by high wind speed and retaining 53\% and 64\% surplus net radiation in the months of April and November respectively. Hence, this would result to an increase in air temperature at Port Harcourt. On the average, $42 \%$ of the surplus net radiation is transferred, in order to maintain thermal equilibrium, while $58 \%$ of the surplus net radiation is retained in Port Harcourt as presented in Figure 3.

\section{Mean Reoccurrence Time (days).}

The mean reoccurrence times (in days) are the number of days it takes for a given state to reoccur. It takes 2.48 and 1.68 days for surplus net radiation conditioned on high and low wind speed respectively, to reoccur in the 
months of May and August. Also it takes 2.54 and 1.65 days for surplus net radiation conditioned on high and low wind speed, to reoccur in the months of September and October. Lastly, it takes 2.13 and 1.88 days for surplus net radiation conditioned on high and low wind speed, to reoccur in the month of April as presented in Figure 4. This means that, the month of April will be hot for 2.13 days and cool for 1.88 days, while the month of August is hot for 1.68 days and cools for 2.48 days. This could possibly explain why the month of April is hot compared to the month of August. On the average, the mean reoccurrence times (days) for surplus net radiation conditioned on high and low wind speed to reoccur is 2.40 and 1.72 days respectively.

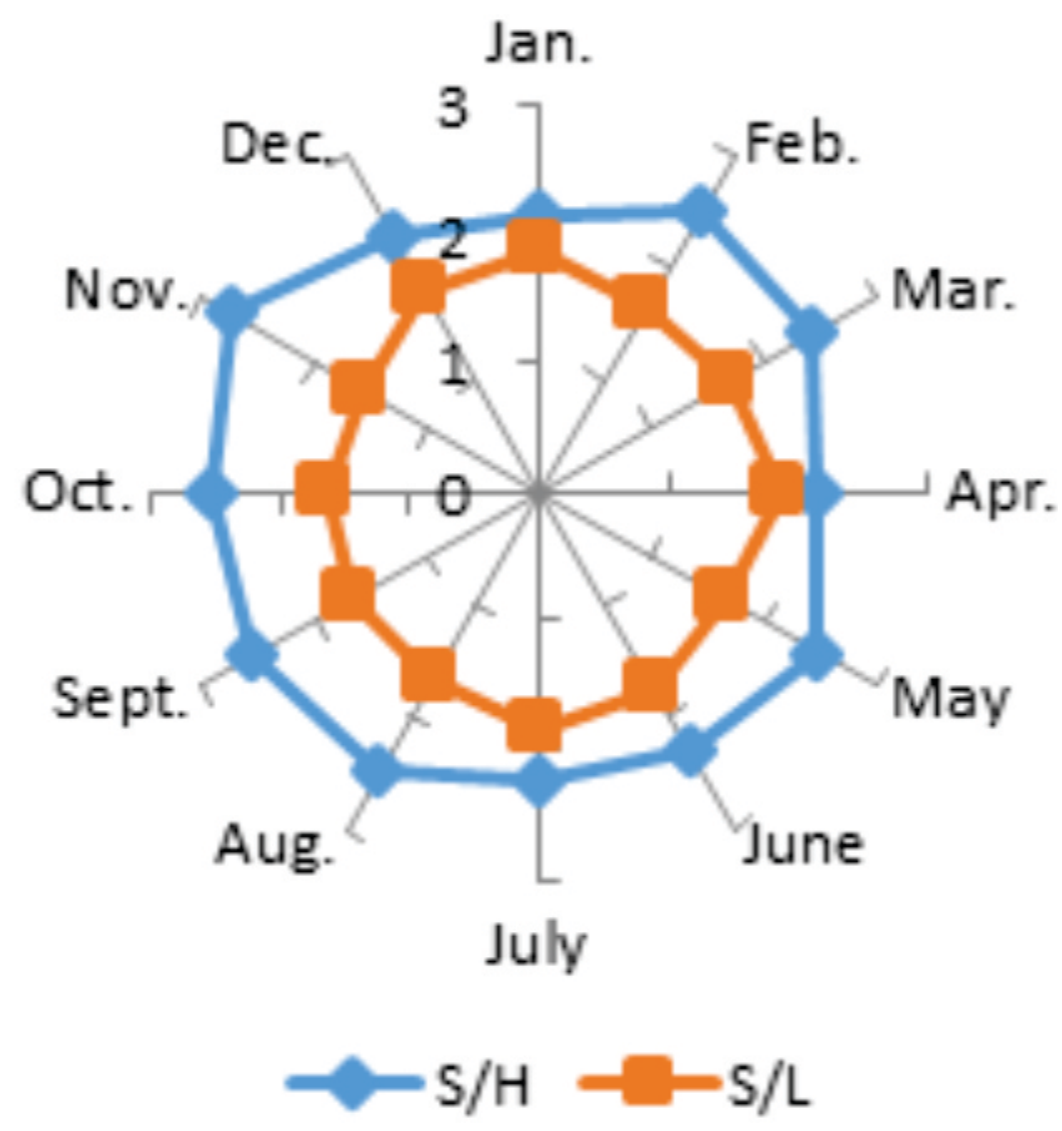

Figure 4: Monthly mean reoccurrence times (days) of Surplus net radiation conditioned on High or Low wind speed $(\mathrm{S} / \mathrm{H}$ and $\mathrm{S} / \mathrm{L})$.

This indicates that, Port Harcourt would be hot for 2.40 days and cool for 1.72 days on the average all through the year, resulting to a hot weather. This could perhaps explain why Akpan and Ebito (2014) stated that the dry season (November to April) is characterized by higher solar radiation and temperature, which agrees with our result. A limitation of their work lies on the inability of the authors to quantify the proportion of net radiation and the mean recurrence time responsible for the aforementioned hotness. They used the Shuttleworth equation to estimate the rate of evaporation in Port Harcourt, Nigeria using ten years (2001 -2010) data on evaporation, temperature, relative humidity, wind speed and solar radiation.

\section{Study Implication}

The amount of incoming solar radiation absorbed by the earth's surface is far greater than the amount of terrestrial radiation emitted in Port Harcourt as shown in Figure 1. Surplus net radiation tends to increase the air temperature at Port Harcourt, thereby increasing the rate of evaporation of energy, water vapour, evapotranspiration and affecting every aspect of life (human, plants and animals). Figure 3 reveals that $46 \%, 40 \%, 41 \%, 47 \%, 40 \%, 44 \%$, $45 \%, 40 \%, 39 \%, 39 \%, 36 \%$ and $44 \%$ of the surplus net radiation are transferred by high wind speed from Port Harcourt to deficit regions 
in the months of January, February, March, April, May, June, July, August, September, October, November and December respectively. This maintains the air temperature in Port Harcourt. The surplus net radiation that is retained in Port Harcourt is more compared to the surplus net radiation transferred to deficit net radiation regions. This result agrees with the work of Uko and Tamunobereton-Ari (2013). They observed that the dry season months (November to February) is shorter and hotter as the year progresses.

Generally, increase in air temperature is likely to have negative effects on yields of crops in some region, but crops in other regions may benefit. The duration of the growing season of any crop in any given location refers to the number of days (mean reoccurrence time) when crop growth takes place. The growing season determines which crops can be grown in a region, as some crops need lengthy growing seasons, while others mature quickly. Depending on the area and the climate, the growing season of any crop is influenced by rainfall, frost days, air temperatures and sunshine hours. The changes in the duration of the growing season of plant can have both negative and positive effects on the yield and prices of particular crops in any region. According to Agada et al. (2016), 40\% of the rural inhabitants are committed to agricultural activities in River state. A variety of short season crops including cocoyam, water yam, sweetpotato, groundnut, maize, sugar-cane and assorted vegetables are grown in Port Harcourt. A continuous increase in air temperature in Port Harcourt can affect all these crops negatively (Amanchukwu, 2015).

Many studies have identified the Niger Delta region as highly vulnerable to impacts of climate change, such as, increased sea level, increased precipitation, coastal erosion, flooding and intensive industrial activities from oil exploration (increased greenhouse gases) (Matemilola, 2019). Greenhouse gases entrap heat in the lower atmosphere and cause positive radiative forcing. In response to increase in concentrations of heat-trapping greenhouse gases, the average air temperatures in Port Harcourt is increasing and its likely to continue rising. Riziki (2010) observed that people living in flood-prone regions are exposed to floodrelated health hazards such as dysentery and cholera. Since climate change can shift the ocean currents and wind patterns that drive the world's climate system, some areas would become warmer or cooler than other. A warmer temperature is one of the main direct signs that the climate is changing (U.S.E.P.A., 2016). This work reveals that Port Harcourt air temperature is becoming warmer as a result of surplus net radiation.

\section{Conclusion}

Net radiation is surplus from January to December in Port Harcourt. The transition probabilities of surplus net radiation condition on low wind speed transiting into the same state dominates from January to December. Also, the monthly steady state probabilities (long run dependence) of surplus net radiation conditioned on low wind speed dominate all through the year. On the average, it takes 2.44 days for surplus net radiation conditioned on high wind speed and 1.69 days for surplus net radiation conditioned on low wind speed to reoccur from January to December. By applying Markov Chain model in this study, we have being able to model net radiation conditioned on wind speed probabilistically using the stochastic approach.

\section{References}

Agada, P.O. Agada, I.O. and Annongu, W.D. (2016). A Model for the Sequence of Positive and Negative Maximum Air temperature Anomaly in Port Harcourt, Nigeria. Int. J. Comp. Theo.Stat. 3(2).101-110.

Amanchukwu, R. N. (2015). Climate change education in Nigeria: The role of curriculum review. Education, 5(3): 7179.

Akpan, U. E. and Ebito, A. J. (2014). Estimation of Evaporation rate using Shuttleworth Equation. World Journal of Applied Science and Technology, 6 (1), 100-104

Balzter H. (2000). Markov chain models for vegetation dynamics. Ecological Modelling, 126(2):139-154.

Cooper P. I. (1969). The Absorption of Solar Radiation in Solar Stills. Journal of Solar Energy, 12 (3).

Crommelin D. and Khouider B. (2015). Stochastic and Statistical Methods in 
climate, Atmosphere, Ocean Science. Applied and Computational Mathematics. 1377-1386

D'Amico G., Filippo P. \& Flavio P. (2012). First and second order semi-Markov chains for wind speed modeling.

Danilton, L. F., Maiara, K. A. R., Eder, C. and Carlos R. F. (2018). Empirical methods for estimating reference surface net radiation from solar radiation. Engenharia Agrícola, Jaboticabal, 38(1), 32-37.

Dechsiri, C., Ghione, A., Van de Wiel, F and Dehling, H.G. (2005). 'PET Investigating of a fluidized particle: Spatial and temporal resolution and short term motion'. Meas. Sci. Technol., 16, 851-858.

Galvão, J.A.C. and Fisch, G. (2000). Radiation Balance in Pasture in the Amazon. Revista Brasileira de Agrometeorologia, 8, 1-10.

Gavilán, P., Berengena, J. and Allen, R.G. (2007). Measuring versus Estimating Net Radiation and Soil Heat Flux: Impact on Penman-Monteith Reference ET Estimates in Semiarid Regions. Agricultural Water Management, 89, 275-286. http://dx.doi.org/10.1016/i. agwat.2007.01.014

Iqbal, M. (1983). An Introduction to Solar Radiation, Academic, Toronto.

John A. D. \& William A. B. (2013). Solar Engineering of Thermal Processes Fourth Edition. John Wiley \& Sons, Inc. Published.

Lincoln Z., Michael D. D., Consuelo C. R., Kati W. M., and Kelly T. M. (2015). Step by Step Calculation of the PenmanMonteith Evapotranspiration (FAO-56 Method). Journal of Agricultural and Biological Engineering Department, UF/IFAS Extension.

Matemilola, S. (2019). Mainstreaming climate change into the EIA process in Nigeria: Perspectives from projects in the Niger Delta Region. Climate, 7(2), 29. https://doi.org/10.3390/cli7020029

Nortazi S., Azami Z., \& Kamaruzzaman S. (2013). An Initial Review: Stochastic Application in Wind Speed Forecasting Recent Advances in Energy, Environment and Development. 82-86

Oyewole, J.A. and Aro, T.O. (2018).Wind Speed Pattern in Nigeria (A Case Study of Some Coastal and Inland Areas). $J$. Appl. Sci. Environ. Manage. 22 (1) 119123.

Philip, E. B. and Hazel, E. T. (2015). The climatological relationships between wind and solar energy supply in Britain. Renewable Energy, 87(1): 96-110.

Riziki, S.S. (2010). Community-based flood risk strategies in Tanzania. Jotoafrica 3( 4).

Ross S. (2010). Introduction to Probability Models. Elsevier Inc., $10^{\text {th }}$ edition.

Santiago, A.V., Pereira, A.R., Folegatti, M.V. and Maggiotto, S.R. (2002) Reference Evapotranspiration Measured with a Weighing Lysimeter and Estimated by Penman-Monteith (FAO-56) on a Monthly and Ten-Days Time Scales. Revista Brasileira de Agrometeorologia, 10, 57-66.

Spencer J. W. (1971). Fourier Series Representation of the Position of the Sun. Search, 2 (5), pp172.

Uko, E.D. and Tamunobereton-Ari, I. (2013). Variability of Climatic Parameters in Port Harcourt, Nigeria. Journal of Emerging Trends in Engineering and Applied Sciences (JETEAS) 4(5): 727730.

Udom, A.U. (2010). Elements of Applied Mathematical Statistics. ICIDR Publishing House Akwa Ibom.

Von Randow, R.C.S. and Alvalá, R.C.S. (2006) Estimation of Long-Wave Atmospheric Radiation over Pantanal Sul Mato Grossense during the Dry Seasons of 1999 and 2000. Revista Brasileira de Meteorologia, 21, 398-412. 